\title{
Health-related quality of life assessment when implementing ecology programs
}

\author{
Vladimir Luchkevich*, Galina Marinicheva, and Vladimir Filatov
}

North-Western State Medical University named after I.I. Mechnikov, Piskarevskij prospect, 47, 195067, St. Petersburg, Russia

\begin{abstract}
The article presents the results of the analysis of the priority health-related quality of life criteria of metropolis residents (St. Petersburg), who live on the territories under the environmental risk and have the signs specific for respiratory diseases. The survey targets analyzing the severity of the main functioning types in the health-related quality of life structure taken in conjunction with the environmental factors. The clinical and statistical analysis and screening questionnaire were performed with the use the specialized questionnaire WHO, to identify the risk factors, the prevalence of the clinical symptoms and chronic respiratory diseases. The importance of the impact was established with deterioration of the life quality indicators at various degrees of the clinical status of the patients at the chronic respiratory disease development stages. The priority health-related quality of life assessment criteria were developed by the types of functioning, providing for classification of the urban residents by medical and environmental risk groups. Insufficient medical awareness and medical preventive care of urban residents were found to increase the impact of the adverse environmental factors on the development of the respiratory diseases. The revealed regularities allowed developing the medical and environmental programs for organizational and functional interaction of the experts.
\end{abstract}

\section{Introduction}

Modern risk-oriented methodology of the feasibility of distribution of population by groups, objects and territories of risk $[8,9,17]$. Need to be methodical and scientific explanation of complex medico-social, hygiene and ecological regional studies with the use of integrated quantitative and qualitative indicators of health and health-related quality of life of the population of administrative territories with high anthropogenic load, which can serve as criteria of effectiveness of implementation of regional environmental programs [1, $14,16,21]$.

\footnotetext{
* Corresponding author: luchkevich@mail.ru
} 


\section{Materials and Methods}

The stages of an integrated research methodology was used for assessing the quality of life related to health $[10,20]$, as an integral subjective measure of satisfaction with the living conditions of the habitat when exposed to risk factors $[6,13]$. Developed and tested a multidimensional generic questionnaire study of health-related quality of life, consisting of 15 scales [10] used for comparative analysis of the severity of the main types of functioning (social-hygienic, physical, social adaptation, recreational activities, emotional state) of urban residents. The assessment of health and specific environmentally related clinical and functional abnormalities affecting the client satisfaction with the health-related quality of life in their respective habitat conditions $[8,11,22]$. The performed integrated ecologicalhygienic and medico-social analysis using risk assessment methodology provided for classification of the urban residents (factor analysis) by risk groups (well-being, relative and absolute risk). For the formation of integral indicators of life quality significance criteria of quantitative and qualitative characteristics (on a 100-point scale) were defined, allowing to distribute urban residents, taking into account the severity, duration and frequency of exposure to adverse factors of living conditions and habitat $[15,17]$. On the basis of clinical-statistical and medical-sociological analysis the prevalence of chronic diseases and specific clinical symptoms was studied among the surveyed urban residents with their classification by health groups [2]. The revealed information importance criteria were used to evaluate the severity of the impact of risk factors on the integral indicator of health-related quality of life [5, 19]. A screening questionnaire [3] was conducted the specialized questionnaire WHO "Burden of major Respiratory Diseases Who Survey" (GARD program) among a representative sample (3032 people) of the population in administrative districts of St. Petersburg with different severity of ecological trouble (by atmospheric air indicators). Adequate methods were used in the course of the comprehensive study to evaluate the reliability, to identify the correlations, to estimate the relative risk, as well as to perform the dispersive and cluster analysis. The detected regularities have allowed developing the organizational-environmental model and the algorithm of the influence of environmental risk factors on the formation of ecologicallycaused chronic respiratory diseases with deterioration of the life quality indicators of the residents of various environmental risk groups $[18,21]$.

\section{Results and Discussions}

Based on the results of the hygiene and environmental studies the priority environmental factors were identified that had the greatest differences in concentrations and health risk criteria $[6,17,19]$. The high proportion of urban residents $(71,4 \%)$ are marking the impact on their health adverse environmental factors environment. According to subjective estimates of urban dwellers the most important (ranked) factor characteristics that affect the development of chronic respiratory diseases, determined their living conditions within major highways $(12,8 \%)$ and industrial companies $(9,0 \%)$. The screening questionnaire conducted among urban residents, revealed that the probability of the formation and development of the chronic respiratory diseases affecting the health-related quality of life indicators $(\mathrm{RR}=2,11$ at $\mathrm{p}=0,01)$ was considerably higher in the group of urban residents, who lived in environmentally unfavorable territories, smoked and had insufficient medical awareness. The surveyed residents identified the most common symptoms: cough, frequent sneezing and nasal congestion, attacks of shortness of breathing, whistling breathing, 
sputum production, with a high proportion of the group absolute risk $(9,0-14,0 \%)$ and significantly predicted risk probability (RR) the specific influence factor.

It was identified that living in ecologically unfavorable territories (absolute risk) leads to increased prevalence of chronic respiratory diseases with the impairment (reduction) of the integral indicators of health-related quality of life and physical functioning, recreational activities and intensity of symptoms (from 42,6 $\pm 9,2$ points, group absolute risk in environmentally disadvantaged areas, to $63,9 \pm 6,1$ scores relatively well on air administrative districts of Saint Petersburg, previously calculated and adopted for the indicative standard for urban residents $-64,7 \pm 0,4$ points). It is noted that the impact of environmental factors of the urban environment contribute to increasing the incidence and other chronic diseases for specific preclinical, clinical and functional manifestations, which you can change and add as we have developed the program for the study health-related quality of life.

When scoring the types of functioning of urban residents living in areas of the environmental risk, the following adverse characteristics health-related quality of life (Table 1) were more pronounced: satisfaction with the conditions of life and economic support $(66,8 \pm 0,09$ points), deterioration of the physical functioning $(71,4 \pm 0,1$ points), psychological and emotional state $(71,9 \pm 0,08$ points), ability to carry out recreational and preventive activities $(71,1 \pm 0,08$ points $)$

Table 1. Significance indicators of the main types of functioning in the structure of the health-related quality of life of urban residents (in points)

\begin{tabular}{|l|c|}
\hline Types of functioning & Points \\
\hline Social and hygienic functioning & $73,2 \pm 0,07$ \\
\hline Social and economic wellbeing & $66,8 \pm 0,09$ \\
\hline Physical functioning & $71,4 \pm 0,1$ \\
\hline Psycho-emotional wellbeing & $71,9 \pm 0,08$ \\
\hline Preventive activity and recreation & $71,1 \pm 0,08$ \\
\hline $\begin{array}{l}\text { Symptoms, prenosological and pathological } \\
\text { conditions }\end{array}$ & $73,9 \pm 0,08$ \\
\hline Indicators of general health & $59,9 \pm 0,09$ \\
\hline Medical activity to strengthen health & $62,2 \pm 0,08$ \\
\hline General quality of life indicators & $64,7 \pm 0,09$ \\
\hline
\end{tabular}

The level of the subjective health assessment $(59,9 \pm 0,09$ points $)$ and general assessment of the health-related quality of life was noted to be low, especially in case of the chronic respiratory diseases $(64,7 \pm 0,09$ points). Then estimating the composite indicators of the health-related quality of life, only $10,9 \%$ of urban residents were related to the well-being group. At that, the relative risk group accounted for the main share of $83,1 \%$. The absolute risk group by the health-related quality of life assessment included $6 \%$ of urban residents.

In the comparative analysis of the dynamics of the health-related quality of life indicators of urban residents after the hygienic, medical-preventive and environmental measures, the subjective assessment level of the severity of specific symptoms and disease states was noted to reduce, while the physical functioning, psychological and emotional state and satisfaction with living conditions improved (the efficiency ratio of 55,9\%).

The research process revealed a high proportion of urban inhabitants $(21,9 \%$ of group absolute risk and 35,2\% group relative risk) in terms of environmental and health awareness. It was found that subjective assessment of satisfaction with health-related quality of life (for basic operation) is significantly greater among residents with higher level 
of environmental and health awareness of the impact of risk factors [5, 7], measures of recreational and preventive activity, development of skills and motivation to health oriented activities (the integral indicator of health-related quality of life with a low level of awareness and insufficient recreational activities was $36,5 \pm 1,8$ points, while with a high level it was $75,3 \pm 1,4$ points $(\mathrm{p}<0.001))$.

\section{Conclusions}

The revealed regularities indicate that the living conditions of the urban residents on the environmental risk territories (by atmospheric air indicators) contribute to the development and prevalence of the specific symptoms of the chronic respiratory diseases [4] with lower subjective assessment levels of satisfaction with health-related quality of life. The regional organizational model and the algorithm of ecological safety shall be implemented (in accordance with the rating) using the methodology of process approach with the definition of participants of the environmental impact (population group), definition of types and levels of exposure to risk factors (climatic, living conditions, lifestyle, professional activity, environment), the formation of the program and phases of environmental security (methods of medical and sociological, hygienic, epidemiological and mathematical analysis of the prevalence of disease and specific clinical and functional states), the development of methods for integrated assessment (health-related quality of life indicators by type of operation), environmental awareness and motivation of the population to health oriented activities continuity, complexity and organizational functional interaction of specialists in the optimization of life support system.

\section{Recommendations}

The proposed methods for objective and subjective assessment of the environmental situation can be used in the formation of regional socio-hygienic monitoring subject to risk assessment methodology [11, 19]; while conducting environmental impact assessments; when planning events with classification of territories with consideration of the environmental risk $[12,15]$. The health oriented environmental activities should include the establishment of public environmental awareness [4, 7], prevention of risk factors of the living conditions and the habitat using a health risk assessment methodology $[11,13]$. Management is the use of methods for the assessment of health indicators and healthrelated quality of life as integral criteria of effectiveness of implementation of environmental and preventive regional programmes $[14,19]$.

\section{References}

1. E. I. Budanova, A. V. Bogomolov, Hygiene and Sanitation, 95 (7), 627-632 (2016) DOI: 10.18821/0016-9900-2016-95-7-627-632

2. E. A. Chanchaeva, O. V. Gvozdareva and A. Yu. Gvozdarev, Human Ecology, 11, 1219 (2019) DOI: 10.33396/1728-0869-2019-11-12-19

3. A. Chuchalin, N. Khaltaev, N.Antonov et al., International Journal of COPD, 9, 963974 (2014) DOI: 10.2147/COPD.S67283

4. S. A. Druzhilov, Hygiene and Sanitation, 97 (7), 597-603 (2018) DOI: 10.18821/00169900-2018-97-7-597-603 
5. S. A. Druzhilov, Hygiene and Sanitation, 98 (7), 748-753 (2019) DOI: 10.18821/00169900-2019-98-7-748-753

6. V. N. Fedorov, E. V. Zibarev, Yu. A. Novikova, A. A. Kovshov, K. B. Fridman and O. V. Slusareva, Hygiene and Sanitation, 96 (7), 614-619 (2017) DOI: 10.18821/00169900-2017-96-7-614-619

7. S. O. Gapanovich, V. F. Levchenko, Principles of the Ecology, 4, 4-16 (2017) DOI: 10.15393/j1.art.2017.5662

8. A. V. Ivanenko, E. V. Sudakova, S. A. Skvortsov, E. V. Bestuzheva, Hygiene and Sanitation, 96 (3), 206-211 (2017) DOI: 10.18821/0016-9900-2017-96-3-206-211

9. A. V. Kiselev, Ya, V, Grigoreva, Hygiene and Sanitation, 96 (4), 306-309 (2017) DOI: 10.18821/0016-9900-2017-96-4-306-309

10. V. S. Luchkevich, G. N. Marinicheva, I. L. Samodova, A. M. Shakirov, A. V. Zelionko Hygiene and Sanitation, 96 (4), 319-324 (2017) DOI: 10.18821/0016-9900-2017-96-4319-324

11. P. I. Melnichenko, A. M. Bolshakov, V. D. Meleshenko, I. K. Ostapovich, T. M. Khodykina, Hygiene and Sanitation, 98 (4), 353-358 (2019) DOI: 10.18821/0016-99002019-98-4-353-358

12. O. V. Mironenko, A. V. Kiselev, S. N. Noskov, A. V. Pan'kin, Kh. K. Magomedov, Z. N. Shengelia, S. N. Myakisheva, Vestnik SPbSU Medicine, 12 (4), 419-428 (2017) DOI: $10.21638 / 11701 /$ spbu11.2017.410

13. V. N. Movchan, P. S. Zubkova, V, M, Pitulko, Vestnik SPbSU Earth Sciences, 62 (3), 266-279 (2017) DOI: 10.21638/11701/spbu07.2017.304

14. N. L. Perelman, Bulletin Physiology and Pathology of Respiration, 72, 112-119 (2019) DOI: 10.12737/article_5d0ad216a56793.64561711

15. I. A. Pogonysheva, D. A. Pogonyshev, Hygiene and Sanitation, 98 (5), 473-477 (2019) DOI: $10.18821 / 0016-9900-2019-98-5-473-477$

16. N. I. Prokhorov, V. I. Dontsov, V. N. Krutko, T. M. Khodykina, Hygiene and Sanitation 98 (7), 761-765 (2019) DOI: 10.18821/0016-9900-2019-98-7-761-765

17. V. V. Suchkov, E. A. Semaeva, Hygiene and Sanitation, 96 (8), 729-733 (2017) DOI: 10.18821/0016-9900-2017-96-8-729-733

18. M. V. Yarigina, P. F. Kiku, A. V. Reshetnikov, Sociology of medicine, 15 (1), 19-24 (2016) DOI 10.1016/1728-2810-2016-15-1-19-24

19. N. V. Zaitseva, P. Z. Shur, I. V. May, D. A. Kiryanov, Hygiene and Sanitation, 95 (1), 106-112 (2016) DOI: 10.18821/0016-9900-2016-95-1-106-112

20. Urban green space interventions and health: A review of impacts and effectiveness 2017 URL: http://www.euro.who.int/_data/assets/pdf_file/0010/337690/FULL-REPORTfor-LLP.pdf?ua=1

21. World Health Organisation European Region Office 2016, The European Environment and Health Process, URL: http://www.euro.who.int/ru/health-topics/environment-andhealth/pages/european-environment-and-health-process-ehp

22. World Health Organisation European Regional Office European Database «Health for Everyone» 2016, URL: https://www.who.int/news-room/detail/27-09-2016-whoreleases-country-estimates-on-air-pollution-exposure-and-health-impact 